\title{
Theoretical and empirical justification of hydrogen atom planetary model
}

\author{
(C) Alexey A. Potapov \\ Butlerov Science Foundation. Bondarenko, St. 33-44. Kazan, 420066. Russia. \\ Phone: +7 (843) 231-42-30; +7 (395) 246-30-09. E-mail: aleksey.potapov.icc@gmail.com
}

Keywords: hydrogen atom, planetary model, atomic constants, stability.

\begin{abstract}
The basis for the hydrogen atom planetary model, which represents the development of the RutherfordBohr atom model, is presented. The measurements of the atom polarizability, radius, electric and magnetic moments, as well as the Stark and Zeeman effects are given as an argument. The central paragraph of the Article is a comparison of the binding energy obtained based on wave measurement data (the Rydberg constant) and the binding energy obtained by calculation according to the data of the electron charge and mass fundamental constants and applying the principle of momentum conservation. The substantiation of the atom stability is given proceeding from the atom planetary model. The nature and mechanism of the optical spectrum formation is discussed. The substantiation of the fine structure of the hydrogen atom spectral lines is presented, proceeding from the fundamental association between the electric field strength of the electron charge and the speed of its velocity. The origin of the optical spectrum hyperfine structure is discussed within the planetary model.

The difficulty in constructing an acceptable theory of the electronic structure of atoms is primarily due to the complexity of obtaining direct information on the atoms internal structure. The point is that the outermost electron shell of an atom behaves itself like an effective screen for external probing electrical fields. This circumstance sharply limits the possibilities of experimental methods for studying the intra-atomic structure. On the other hand, it is imperative that the research methods being employed be non-destructive ones in order to obtain reliable information concerning the structure of atoms. This means that the action on the atom during measurement process must meet the condition of the electron shell perturbation smallness of the atom or ion being investigated. Concerns associated with the inaccessibility of the electronic structure of atoms served as a pretext for a conclusion of the limited possibilities of the empirical method of knowing the internal structure of atoms at the proper time.
\end{abstract}

\section{References}

[1] V. Heisenberg. Physics and Philosophy. Part and Whole. Moscow: Nauka. 1989. 400p. (russian)

[2] R. Penrose. Way to reality or laws governing the universe. Moscow-Izhevsk: Russian Christian Movement. 2007. 912p. (russian)

[3] I. Lakatos. Falsification and methodology of research programs. In the book: Kun T. Structure of scientific revolutions. Moscow: AST Publishing House, LLC. 2001. 608p. (russian)

[4] L. Accardi. Dialogues on quantum mechanics. Heisenberg, Feynman, Academus, Candido and Chameleon on a branch. Moscow-Izhevsk: Institute of Computer Research; R\&D establishment "Regular and chaotic dynamics". 2004. 448p. (russian)

[5] A.A. Potapov. Fundamental bases of the structure of substance. Butlerov Communications. 2015. Vol.41. No.2. P.1-29. DOI: 10.37952/ROI-jbc-01/15-41-2-1

[6] A.A. Potapov. Renaissance of a classical atom. Moscow: Nauka Publishing House, LAP LAMBERT Academic publishing. 2011. 444p. (russian)

[7] A.A. Potapov. Nature and mechanisms of atomic binding. Moscow: RIOR: INFRA-M. 2013. 295p. (russian)

[8] A.A. Potapov. The science of matter: overcoming the crisis. In the collection "Actual problems of biology, chemistry, physics": materials of the international research and practice conference. Novosibirsk: EKOR-kniga Publishing house. 2011. P.136-148. (russian)

[9] A.A. Potapov, and Yu.V. Mineev. Planetary model of the hydrogen atom and hydrogen-like structures. Butlerov Communications. 2015. Vol.44. No.11. P.1-15. DOI: 10.37952/ROI-jbc-01/15-44-11-1

[10] C. Kittel et al. Mechanics. Moscow: Nauka. 1983. 448p. (russian) 
[11] B. Taylor et al. Fundamental constants and quantum electrodynamics. Moscow: Atomizdat. 1972. 328p. (russian)

[12] E. Cohen. Determination of the best values of fundamental constants. Harmonization of the fundamental constants values. In the collection of Quantum Metrology and Fundamental Constants. Moscow: Mir. 1981. P.122-340. (russian)

[13] A.A. Potapov. Dielectric method of substance research. Irkutsk: Irkutsk University Publishing House. 1990. 256p. (russian)

[14] A.A. Potapov. Deformational polarization: the search for new models. Novosibirsk: Nauka. 2004. 511p. (russian)

[15] A.A. Potapov. Radius of the hydrogen atom: a fundamental constant. Science, technology and education. 2015. No.10. P.7-16. (russian)

[16] A.A. Potapov. Orientational polarization: the search for new models. Novosibirsk: Science. 2000. 336p. (russian)

[17] A.A. Potapov. Revisiting the spin of an electron. The path of science. 2015. No.11. P.19-28. (russian)

[18] A.A. Potapov. Optical Spectrum of the Hydrogen Atom: Nature and Formation Mechanism. Science and World. 2015. Vol.1. No.11. P.13-28. (russian)

[19] Physical encyclopedical dictionary. Moscow: Soviet Encyclopedia. 1983. 928p. (russian)

[20] A. Sommerfeld. The structure of an atom and spectra. Vol.1. Moscow: Publishing House of Technical and Theoretical Literature. 1956. 592p. (russian)

[21] A.A. Potapov. The nature and mechanism for formation of Stark and Zeeman effects. Science and World. 2016. Vol.1. No.1. P.32-41. (russian)

[22] E. Purcell. Electricity and magnetism. Moscow: Nauka. 1975. 440p. (russian)

[23] N.N. Moiseev. Parting with simplicity. Moscow: Agraf. 1998. 480p. (russian)

[24] V.V. Demyanov. Ether-dynamic secrets of relativistic and quantum theories. Novorossiysk: Maritime State University named after Admiral F.F. Ushakov, Russian Historical Society. 2006. 462p. (russian)

[25] J. Orir. Physics. Moscow: Mir. 1981. 624p. (russian)

[26] S.E. Frish. Optical spectra of atoms. Moscow-Leningrad: Fizmatlit. 1963. 640p. (russian) 